\title{
Ecological engineering across organismal scales: trophic-mediated positive effects of microhabitat enhancement on fishes
}

\author{
Daisuke Taira ${ }^{1}$, Eliza C. Heery ${ }^{1,2}{ }^{,}$Lynette H. L. Loke ${ }^{1,3}{ }^{,}$Aaron Teo ${ }^{1}$, \\ Andrew G. Bauman ${ }^{1}$, Peter A. Todd ${ }^{1, *}$ \\ ${ }^{1}$ Department of Biological Sciences, National University of Singapore, Singapore 117543, Singapore \\ ${ }^{2}$ Present address: Friday Harbor Laboratories, University of Washington, Friday Harbor, WA 98250, USA \\ ${ }^{3}$ Present address: Department of Earth and Environmental Sciences, Macquarie University, Sydney, NSW 2109, Australia
}

\begin{abstract}
Retrofitting microhabitat features is a common ecological engineering technique for enhancing biodiversity and abundance of small, epilithic organisms on artificial shorelines by providing refuge spaces and/or ameliorating abiotic conditions. These features are typically too small to be utilised as refugia by larger, highly motile consumers such as fish, but they may affect these organisms through other mechanisms. This study sought to determine whether microhabitat enhancement units alter the fish abundance, richness and assemblage composition on tropical seawalls and explores possible underlying trophic mechanisms. We created 12 experimental plots consisting of 6 enhanced plots, each with 20 microhabitat enhancement tiles, and 6 control plots without tiles on intertidal seawalls at Pulau Hantu, an offshore island south of mainland Singapore. Benthic cover and fish assemblage were surveyed within each plot using photoquadrats and underwater video cameras, respectively, from April 2018 to February 2019. We found greater abundance and species richness and distinct assemblages of fish in the enhanced plots compared to the control plots. These differences were driven largely by an increase in both abundance and richness of fish species with epibenthic-feeding strategies and were significantly associated with higher biotic cover in the enhanced plots, especially epilithic algal matrix (EAM). Our results indicate that, in addition to facilitating epilithic organisms, microhabitat enhancement can provide food resources for epibenthic-feeding fishes, increase fish biodiversity, and alter fish assemblages in tropical urbanised shorelines.
\end{abstract}

KEY WORDS: Fish diversity - Fish feeding - Eco-engineering - Coastal defences · Marine urbanisation · Epilithic algal matrix

\section{INTRODUCTION}

The global human population is disproportionately concentrated within coastal regions, due in part to the resources found near river mouths and nearshore zones, but also because the land-sea interface is a strategic location for trade (Duarte et al. 2008, Todd et al. 2019). The growth and expansion of coastal populations worldwide has increased demands for

*Corresponding author: dbspat@nus.edu.sg

$\S$ Advance View was available online October 22, 2020;

subsequently updated October 26, 2020 natural resources, leading to land use changes, pollution and overexploitation of resources (Dafforn et al. 2015, Firth et al. 2016). Consequently, intensified coastal urbanisation and associated pressures (e.g. resource exploitation, pollution and physical modification) are significantly altering marine environments and are a major threat to coastal ecosystems (Burke et al. 2011, Heery et al. 2018, Todd et al. 2019). For example, land reclamation and dredging

(C) The authors 2020. Open Access under Creative Commons by Attribution Licence. Use, distribution and reproduction are unrestricted. Authors and original publication must be credited. 
activities that directly remove/destroy coastal habitats can cause downstream increases in sedimentation levels and eutrophication as well as alter hydrodynamics of local environments (Fabricius 2005, Erftemeijer et al. 2012). The increasing accessibility of urban waterways has also boosted commercial shipping and recreational boating activities, which can impact coastal habitats through sediment resuspension events, introduction of invasive species, ship-grounding incidents and other processes (Riegl 2001, Browne et al. 2014).

The proliferation of artificial structures (or 'ocean sprawl'), one of the key impacts of coastal urbanisation, is transforming natural shorelines in many coastal cities (Bishop et al. 2017). Such transformation occurs at varying spatial scales, ranging from a few metres to hundreds of kilometres, and there is growing concern about its negative impact on marine biodiversity and ecosystem function (Firth et al. 2016). In particular, natural nearshore environments provide foraging and resting grounds for adult fish and nursery grounds for juveniles of fish species that migrate offshore upon maturity (Seitz et al. 2014, Bergström et al. 2016). Fish assemblages often respond strongly to changes in benthos and the structural complexity of benthic habitats (Gratwicke \& Speight 2005, Wilson et al. 2007). Since coastal artificial structures heavily alter benthic composition and structural complexity (Firth et al. 2016), there is a need to better understand their effects on fish assemblages, particularly as they become ubiquitous features of urbanised shorelines.

In recent decades, a number of studies have assessed fish assemblages associated with coastal infrastructure, including marinas (Jaafar et al. 2004, Clynick et al. 2008, Toh et al. 2016), boat moorings (Lanham et al. 2018), jetties (Weis \& Weis 2005), pilings (Toft et al. 2013), seawalls (Munsch et al. 2015a, Benzeev et al. 2017, Porter et al. 2018) and breakwaters (Guidetti et al. 2005, Burt et al. 2009, 2013). Collectively, this research has shown that fish assemblage composition associated with artificial habitats is different from that in natural habitats and suggests that fish populations may be altered by coastal infrastructure in several ways. For example, overwater structures increase shade and disrupt the movement patterns of juvenile salmon (Munsch et al. 2017). The low structural complexity (Firth et al. 2016) and high material homogeneity typical of seawalls is thought to provide few habitat niches for fishes (Porter et al. 2018, Strain et al. 2018b). In addition, armoured shorelines can increase the steepness of adjacent sediments, reducing the availability of shallow habi- tats for predation avoidance (Munsch et al. 2016) as well as altering cross-habitat material fluxes and fish diets (Munsch et al. 2015b). These impacts are often localised but, given the scale of shoreline armouring in major coastal cities, may have negative consequences on overall fish biodiversity in urban coastal systems.

Ecological engineering is a contemporary approach used to increase biodiversity and/or abundance of particular target groups, such as bivalves or fish, on and near artificial coastal structures (Morris et al. 2019). A common technique is to add physical features that increase habitat structural complexity (e.g. Coombes et al. 2015, Loke \& Todd 2016, Loke et al. 2017, Strain et al. 2018b). Since the functional relationship between organisms and their environment is allometric (contingent on body size) (Hixon \& Beets 1993, Ménard et al. 2012, Nash et al. 2013), the effectiveness of these features depends on their size relative to the size of organisms they are intended to accommodate. For instance, while habitat features at the $\mathrm{mm}$ to $\mathrm{cm}$ scale are considered most appropriate for small, epilithic invertebrate and macroalgae assemblages, $\mathrm{cm}$ - to m-scale features are commonly used for fish (Sella \& Perkol-Finkel 2015, Mercader et al. 2017, Morris et al. 2018).

To date, much of the work on coastal ecological engineering has focussed on microhabitat enhancement designs that target small, epilithic organisms (Strain et al. 2018b). The scale of these designs is often too small to act as refugia for larger motile consumers such as fish, but could affect large organisms through other means, particularly by mediating access and availability of food resources. For instance, Ushiama et al. (2019) found that physical complexity from small concrete enhancement tiles $(250 \times 250 \times 20 \mathrm{~mm})$ inhibited cryptobenthic fish feeding by restricting access to their epibenthic prey (e.g. algae and oysters). On the other hand, biotic colonisation of enhancement tiles may enhance food resources for certain groups, such as foraging herbivores and benthic mesopredators, and/or add biogenic structure at a relevant scale for a range of larger mobile consumers (Ushiama et al. 2019).

As microhabitat enhancement units are increasingly deployed on urbanised shorelines (Strain et al. 2018a, Morris et al. 2019), understanding their effect across organismal scales and on functional groups including fish is essential for assessing broader, system-wide consequences of ecological engineering. The few studies that have been undertaken in this field to date have found inconsistent 
results and were limited to temperate regions (Sella \& Perkol-Finkel 2015, Mercader et al. 2017, Morris et al. 2017, Ushiama et al. 2019). Our study evaluated the effect of microhabitat enhancement units on fish assemblages on intertidal seawalls in tropical urban shorelines. To do this, we retrofitted and surveyed experimental plots $(2.4 \times 2.4 \mathrm{~m})$ previously developed by Loke et al. (2019) as enhancements for intertidal invertebrates and macroalgae. Specifically, the objectives were to (1) determine whether microhabitat enhancement units alter fish abundance, richness and composition and (2) quantify fish feeding activity and benthic cover on enhanced versus control plots to explore possible trophic mechanisms underlying patterns observed in (1). We hypothesised that seawall plots with microhabitat enhancement units would support fish assemblages that were compositionally distinct, more diverse, and more abundant than controls. Additionally, we hypothesised these patterns would coincide with increased biotic cover and feeding activity (number of bites) on substrates enhanced with microhabitat features.

\section{MATERIALS AND METHODS}

\subsection{Study sites and experimental design}

This study was conducted in Singapore, a highly urbanised island city-state and global shipping hub located off the southern tip of Peninsular Malaysia (Chou 2008, Bauman et al. 2015). Intensive land reclamation since the 1960 s has resulted in $>63 \%$ of Singapore's shoreline now comprising seawalls (Lai et al. 2015). Fish assemblages associated with artificial coastal structures in Singapore have been documented in a handful of past studies (Jaafar et al. 2004, Toh et al. 2016, Benzeev et al. 2017, Taira et al. 2018). Our research was conducted along the western shoreline of Pulau Hantu $\left(1^{\circ} 13.645^{\prime} \mathrm{N}, 103^{\circ}\right.$ $44.780^{\prime} \mathrm{E}_{\text {; Fig. }} \mathrm{S} 1$ in the Supplement at www. int-res.com/articles/suppl/m656p181_supp. pdf), an island situated approximately $7 \mathrm{~km}$ south of mainland Singapore. Pulau Hantu underwent land reclamation between 1974 and 1975, increasing the total land area from 2.0 to 12.5 ha (Chia et al. 1988) and resulting in substantial losses of reef flats (Lai et al. 2015). Sloping granite riprap seawalls were constructed in order to protect the new shoreline. The areas surrounding the seawall are characterised by a narrow strip of sandy substrate and a fringing reef extending to $6 \mathrm{~m}$ depth.

We repurposed experimental tiles from Loke et al. (2019) to recreate 12 new $2.4 \times 2.4 \mathrm{~m}$ experimental plots spaced at least $20 \mathrm{~m}$ apart from each other: 6 'enhanced' plots, each consisting of 20 concrete enhancement tiles, and 6 'control' plots with no tiles. The microhabitat enhancement tiles $(200 \times 200 \times$ $60 \mathrm{~mm}$ ) used in this study, which were designed to enhance intertidal invertebrate and algal biodiversity, were the same ones deployed by Loke et al. (2019) in 2014. After the end of that experiment in 2015 , they were left in place for another $2 \mathrm{yr}$ to allow the development of mature benthic communities (Loke et al. 2016). In February 2018, we identified the position of the 12 new experimental plots on the seawall where no tiles had previously been installed, and moved the tiles from Loke et al.'s (2019) experimental plots to 6 of the new locations during low tide, following the installation protocol in Loke et al. (2019). To demarcate the area for video analysis, additional bolts were affixed to the seawalls to mark the corners of each $2.4 \times 2.4 \mathrm{~m}$ plot. The 20 tiles in the enhanced plots followed the spatial configuration that achieved one of the most diverse intertidal communities in Loke et al. (2019) (Fig. 1a). All experimental plots were positioned between 0.2 and $1.7 \mathrm{~m}$ above chart datum with a seawall incline of $\sim 30^{\circ}$, following Loke et al. (2019). The tidal height range was
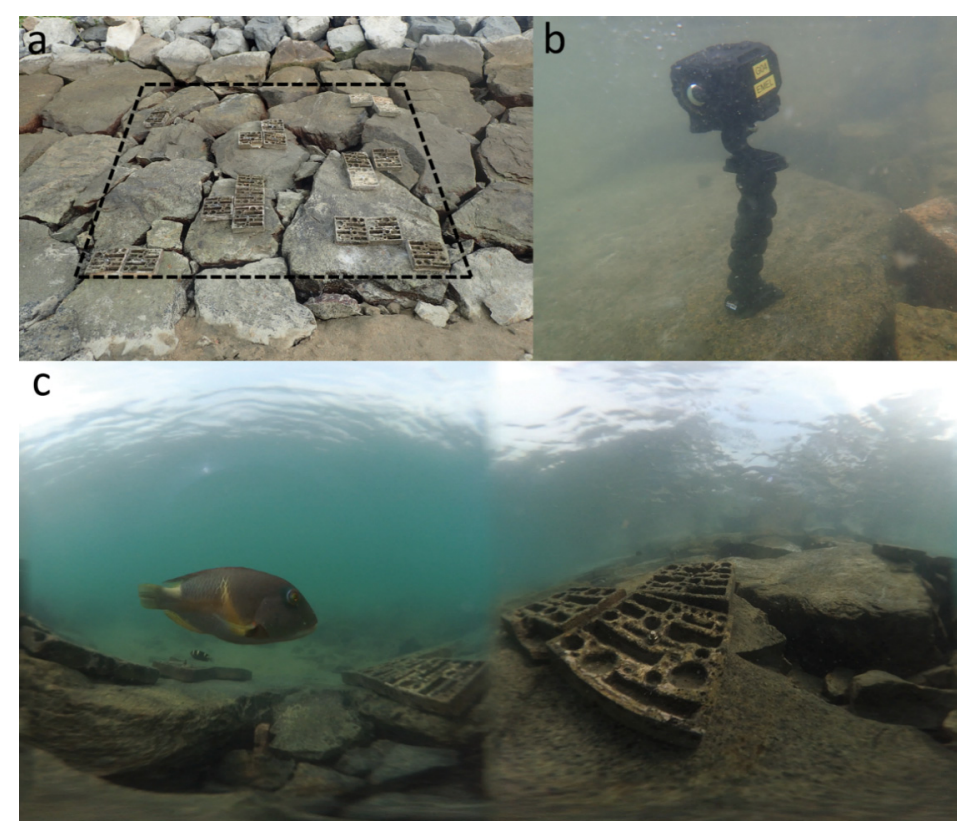

Fig. 1. Experimental setup showing (a) an enhanced plot, (b) underwater camera and (c) screenshot from the video footage 
maintained from the previous study design to minimise disturbance of tiles and ensure that colonising biota were of a similar successional stage across plots. Benthic and fish surveys were conducted from April 2018 to February 2019, monthly for the first 3 mo and every 2 mo subsequently.

\subsection{Benthic cover survey}

In each sampling period, plots were surveyed for benthic cover by collecting 16 photoquadrats $(60 \times$ $60 \mathrm{~cm}$ ) in a grid pattern covering the entire plot area. Coral Point Count with excel extension (CPCe, Kohler \& Gill 2006) was used to generate 20 random points per image (i.e. 320 points plot $^{-1}$ ), and the substrate directly underlying these points was identified to estimate proportional benthic cover. We categorised benthic cover into 7 benthic groups: macroalgae (MA), epilithic algal matrix (EAM), crustose coralline algae (CCA), other biota, sand, silt and rock/tile, modified from Guest et al. (2016).

\subsection{Fish assemblage survey}

To quantify fish assemblages and feeding activities, remote underwater video cameras (RUVs) were used (Tessier et al. 2005, Zarco-Perello \& Enríquez 2019). To capture the entire $2.4 \times 2.4 \mathrm{~m}$ plots, we used $360^{\circ}$ underwater cameras (Garmin Virb 360) with 2 fish-eye lenses. A single camera was placed at the centre of each experimental plot and raised $15 \mathrm{~cm}$ above the substrate using a flexible camera mount (Fig. 1b). Each camera recorded continuously for $\sim 75 \mathrm{~min}$; the first 10 and the last $5 \mathrm{~min}$ of each video were excluded from the analyses to minimise potential diver interference. During each monitoring, we filmed half of the 12 plots first ( 3 control and 3 enhanced, randomly selected) and then the other half on the same day after replacing the camera batteries. The entire monitoring was completed within $3 \mathrm{~h}$.

From the video footage, we counted fish abundance, species richness and the total number of bites for each plot (Fig. 1C). Fish abundance was quantified as MaxN (the maximum number of individuals of a particular species recorded in any single frame of video footage), as it provides conservative estimates and is widely used as a proxy of fish abundance in RUV surveys (e.g. Henderson et al. 2019, Ushiama et al. 2019). Each fish was identified to the lowest possible taxonomic level, mostly to species, from the video footage following the taxonomic classifications by Allen \& Erdmann (2012). Cryptobenthic fish (i.e. gobiids, blennids and tripterygiids) were not counted due to their small size (typically $<5 \mathrm{~cm}$ ), and because their visually and behaviourally cryptic characteristics hindered reliable counts and identification via the video footage. Additionally, fish in large schools and/or near the sea surface were excluded from the analyses. The number of bites on substrates were counted as a proxy for feeding activities of epibenthic-feeding fishes that feed on benthic organisms on the seawall surface (Morais \& Bellwood 2019). Individual bites were defined as the quick movements of the head towards and away from the substrate, following Bellwood \& Fulton (2008). Each epibenthic-feeding fish species was grouped into trophic categories based on Brandl \& Bellwood (2014). Macro-invertivores and micro-invertivores were combined as invertivores. All the video footage was recorded during peak spring high tides $(2.5-3.0 \mathrm{~m}$ above a chart datum) between 10:00 and 15:00 h.

\subsection{Statistical analyses}

All analyses were conducted in R v.3.6.2 (R Core Team 2019). Due to low abundance of most biotic benthic components (i.e. MA, CCA and other biota), all biotic components (i.e. EAM, MA, CCA and other biota) were combined to provide a general indication of 'biotic cover' and compared between enhanced and control plots. To test this comparison, we used generalised linear mixed models (GLMMs) with the 'glmmTMB' package (Brooks et al. preprint doi:10. 1101/132753). The biotic cover data was logit transformed following Smithson \& Verkuilen (2006), and the model was run using a beta distribution with treatment as a fixed effect and time (months) as a random effect. Similarly, fish abundance (sum of MaxN for each species), species richness and total number of bites were analysed using GLMMs with treatment and benthic biotic cover as fixed effects and time as a random effect. GLMMs were run with negative binomial distributions for abundance and the number of bites and with a Poisson distribution for species richness. For all models, the model fit was evaluated by checking residual diagnostic plots using the 'DHARMa' package (Hartig 2019). Akaike's information criterion adjusted for small sample size $\left(\mathrm{AIC}_{\mathrm{C}}\right)$ was used to compare similar models; the model with the lowest $\mathrm{AIC}_{\mathrm{C}}$ value was selected. 
Multivariate analyses of fish assemblage composition were conducted using MaxN abundance for each species. We used multivariate generalised linear models with the 'mvabund' package and the 'manyglm' function due to heterogeneous multivariate variance of the data (Wang et al. 2012). Fish assemblage composition was modelled with a negative binomial distribution with treatment, biotic cover and time as explanatory factors. Since 'mvabund' does not allow addition of random factors, we decided to include time as a fixed effect instead, because, although it was not the main focus of the study, it should be accounted for. To account for repeated measures, individual plots were used to restrict permutations by the block design.

To visualise the assemblage composition patterns, we used multiple factor analysis (MFA) in the 'FactoMineR' package (Lê et al. 2008), a multivariate analysis method where qualitative and quantitative variables are organised into groups of one or more variables. Each variable group was weighted during MFA based on the inverse of its first eigenvalue (Pagès 2004). We created 3 variable groups: treatment (one qualitative variable), benthic cover ( 7 quantitative variables, i.e. proportional cover of each benthic component) and time (one qualitative variable). The weighted variables were then visualised via a biplot, with data ellipses for categorical variables using the 'factoextra' package (Kassambara \& Mundt 2019).

\section{RESULTS}

A total of $10.4 \%$ of surveyed substrate was occupied by epibenthic biota overall, with the remainder consisting of bare rock or concrete tiles $(89.6 \%)$. Biotic benthic cover was dominated by EAM $(10.1 \%)$, whereas CCA, MA (e.g. Sargassum and Padina) and other biota (e.g. sponges and zoantharians) together accounted for $\sim 0.3 \%$ of the cover. Biotic cover was significantly greater in enhanced plots (mean $\pm \mathrm{SE}=17.0 \pm 1.8 \%)$ than control plots $(3.7 \pm 0.6 \%)$ (Table 1a). This difference approximately equalled the plot area occupied by tiles $(\sim 14 \%)$, which were extensively colonised. Biotic cover at both control and enhanced plots fluctuated similarly throughout the study period, with EAM and MA at their lowest in April 2018 and peaking in December 2018 (Fig. 2a). Within enhanced plots, mean biotic cover was comparable between the collective tile surfaces $(8.7 \pm$ $0.5 \%$ biotic cover), which occupied a smaller portion of the plot area, and the non-tile surfaces $(8.3 \pm$ $1.4 \%$ biotic cover), which made up the majority of the plot.

A total of 53 fish species were observed from the $84 \mathrm{~h}$ video footage. Pomacentridae (18.9\%), Labridae $(17.0 \%)$ and Serranidae $(9.4 \%)$ were the most commonly observed fish families. The most abundant species were Dischistodus fasciatus (Pomacentridae), Scarus rivulatus (Scaridae), Choerodon anchorago (Labridae), Abudefduf bengalensis (Pomacentridae) and Mugilidae (Table S1). Treatment and biotic cover had significant positive effects on fish abundance (Table 1b). There was also a significant interaction between these factors. Species richness was significantly greater at the enhanced plots than the control plots and increased with biotic cover, but there was no significant interaction between these variables (Table 1c).

We recorded a total of 14218 bites from 21 epibenthic-feeding fish species including detritivores (De: $93.5 \%$ ), omnivores (Om: $3.5 \%$ ), invertivores (In: $2.7 \%$ ) and herbivores (He: $0.3 \%$ ). The main contributing species $(\sim 99 \%$ of total bites) were D. fasciatus (De: $65.2 \%$ ), S. rivulatus (De: $14.8 \%$ ), Pomacentrus tripunctatus (De: $8.1 \%$ ), Dischistodus

Table 1. Generalised linear mixed models of proportional biotic cover, abundance (MaxN), species richness and total number of fish bites at experimental plots on seawalls at Pulau Hantu, Singapore. Bold indicates $\mathrm{p}<0.05$

\begin{tabular}{|lrrrr|}
\hline Source & Estimated & SE & \multicolumn{1}{c}{$z$} & $\mathrm{p}$ \\
\hline (a) Biotic cover & & & & \\
(Intercept) & -2.1214 & 0.2433 & -8.718 & $<\mathbf{0 . 0 0 0 1}$ \\
Treatment & 1.5843 & 0.2004 & 7.907 & $<\mathbf{0 . 0 0 0 1}$ \\
(b) MaxN & & & & \\
Intercept) & 2.5481 & 0.1073 & 23.753 & $<\mathbf{0 . 0 0 0 1}$ \\
Treatment & 0.2939 & 0.1447 & 2.030 & $\mathbf{0 . 0 4 2 3}$ \\
Biotic cover & 4.7161 & 1.6237 & 2.904 & $\mathbf{0 . 0 0 3 7}$ \\
Treatment $\times$ biotic cover & -3.2512 & 1.6520 & -1.968 & $\mathbf{0 . 0 4 9 1}$ \\
(c) Species richness & & & & \\
Intercept) & 2.1447 & 0.0902 & 23.782 & $<\mathbf{0 . 0 0 0 1}$ \\
Treatment & 0.2699 & 0.1055 & 2.558 & $\mathbf{0 . 0 1 0 5}$ \\
Biotic cover & 3.0097 & 1.2717 & 2.367 & $\mathbf{0 . 0 1 7 9}$ \\
Treatment $\times$ biotic cover & -2.3795 & 1.2765 & -1.864 & 0.0623 \\
(d) Number of bites & & & & \\
(Intercept) & 3.0589 & 0.2882 & 12.454 & $<\mathbf{0 . 0 0 0 1}$ \\
Treatment & 0.8868 & 0.3217 & 2.757 & $\mathbf{0 . 0 0 5 8}$ \\
Biotic cover & 4.9310 & 3.7945 & 1.300 & 0.1938 \\
Treatment $\times$ biotic cover & 0.7450 & 3.8700 & 0.193 & 0.8473 \\
\hline
\end{tabular}



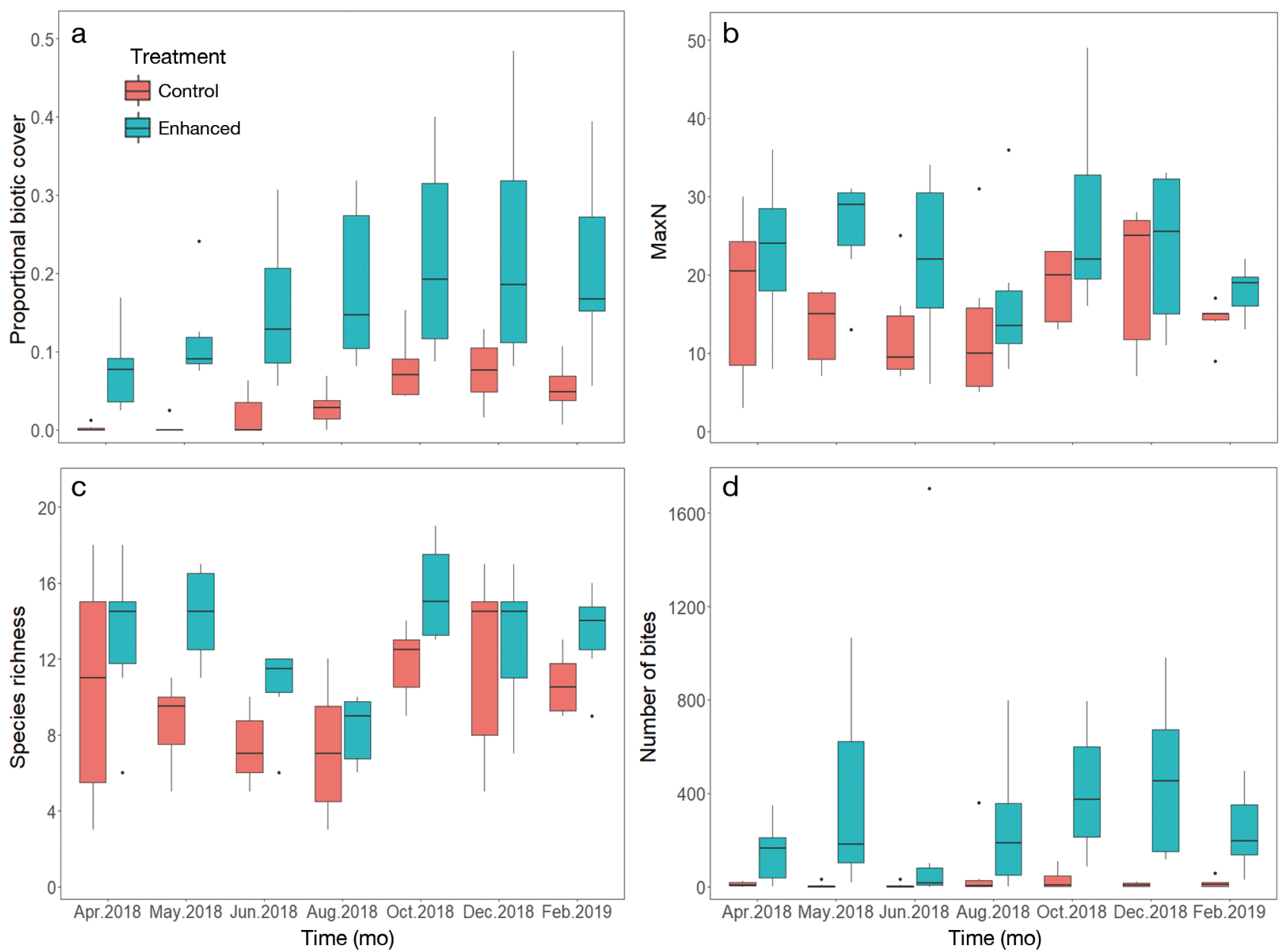

Fig. 2. (a) Proportional biotic cover, (b) fish abundance (MaxN), (c) species richness and (d) number of bites per plot in control and enhanced plots in 7 monitoring periods from April 2018 to February 2019. For each box, upper and lower hinges: $25^{\text {th }}$ and $75^{\text {th }}$ percentiles; bold horizontal line: median; whiskers: minimum and maximum values

chrysopoecilus (De: $4.8 \%$ ), Chaetodontoplus mesoleucus (Om: $2.3 \%$ ), Choerodon anchorago (In: $1.4 \%$ ), A. bengalensis (Om: $1.1 \%)$, Halichoeres chloropterus (In: $0.7 \%$ ), Chelmon rostratus (In: $0.5 \%$ ) and Siganus virgatus (He: $0.3 \%$ ). The total number of bites per plot was significantly greater on enhanced plots than control plots (Table 1d), with most of the major contributor species generally taking more bites in enhanced plots (Fig. 3). Within enhanced plots, $88.2 \%$ of the total bites were taken from the tiles.

Fish assemblage composition was significantly influenced by treatment (deviance $=101.9, \mathrm{p}=0.022$ ), biotic cover (deviance $=132.9, \mathrm{p}=0.001)$ and time (deviance $=641.1, \mathrm{p}<0.001)$. Similar patterns in fish assemblage compositions were apparent in MFA plots of the first 2 dimensions, which accounted for $28.9 \%$ of total variation (Fig. 4). Treatment and benthic cover contributed more to the first dimension whereas time contributed more to the second dimension (Fig. 4a). Abundances of many epibenthicfeeding species were positively correlated with algal cover, especially D. fasciatus, S. rivulatus, C. anchorago, C. mesoleucus and H. chloropterus with EAM and $A$. bengalensis, $D$. chrysopoecilus and $S$. virgatus with MA cover (Fig. 4b). Assemblage composition was distinct between treatments, with a relatively little overlap (Fig. 4c). Among time points, assemblage composition was especially different between April and October 2018, despite substantial overlaps among the remaining months (Fig. 4d).

\section{DISCUSSION}

Findings from the present study suggest that, in addition to enhancing epilithic assemblages, microhabitat features may also increase the local abundance of epibenthic-feeding fish. We detected strong 


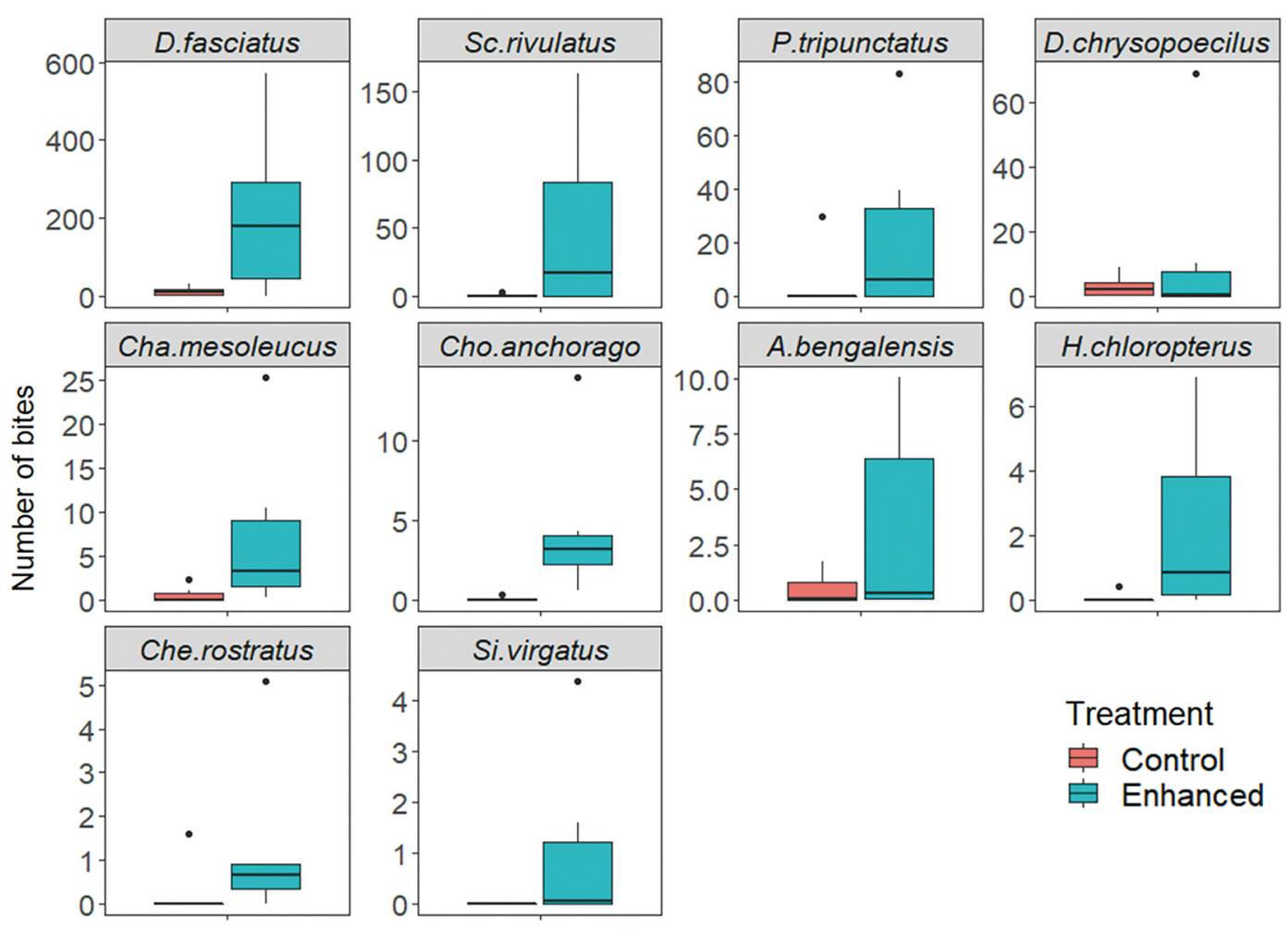

Fish species

Fig. 3. Mean number of bites per plot in control and enhanced plots for the top 10 epibenthic-feeding fish species that contributed to the total bites. Mean bites per plot $\left(n=6\right.$ treatment $^{-1}$ ) were calculated after averaging the number of bites for each study plot across 7 monitoring months. Boxplot parameters as in Fig. 2. A: Abudefduf; Cha: Chaetodontoplus; Che: Chelmon; Cho: Choerodon; D: Dischistodus; H: Halichoeres; P: Pomacentrus; SC: Scarus; Si: Siganus

positive relationships between treatments, biotic cover, feeding activity and the diversity and abundance of fish, and we posit that the positive effect of microhabitat units on fish assemblages was trophicmediated, with enhancement tiles supporting greater cover of EAM that, in turn, supported a variety of epibenthic-feeding fishes. To our knowledge, this study is the first to provide evidence of trophicmediated positive effects of microhabitat enhancement units on fish. Epibenthic-feeding fishes - which made up $40 \%$ of the recorded species in this study were the primary group to drive the difference in assemblage composition between treatments. Significantly higher bite rates in enhanced versus control plots suggest that, in addition to increasing the density of epibenthic-feeders, microhabitat features led to more intense foraging activity. Differences in feeding rate may have been the result of numerous factors, such as increased density and diversity of benthic organisms, as well as greater area and topographic complexity of the seawall surface, which were beyond the scope of this study. However, our results indicate that food resource availability is likely among the factors involved. There was little benthic colonisation on the granite substrate in the control plots, while the installed concrete tiles in the enhanced plots supported dense colonisation and mature growth of epibenthic organisms (mostly EAM) on which most of feeding activity by epibenthic-feeding fishes took place. These results concur with previous findings that the epibenthic food availability is potentially a limiting factor for ecological communities associated with seawalls (Lai et al. 2018).

Microhabitat could have enhanced fish assemblages through a wide variety of mechanisms. The numerous pits and grooves on the tiles may have accommodated more grazing niches for epibenthicfeeding fishes (Fox \& Bellwood 2013, Brandl \& Bellwood 2016). For example, scarids tend to graze on flat or exposed surfaces while siganids are morphologically adapted to feeding on algae associated with crevices or concealed spaces (Bennett et al. 2010, Fox $\&$ Bellwood 2013). It was impossible to determine the identity of the fish diets through the video analyses, but EAM appears to be one of the key epibenthic 

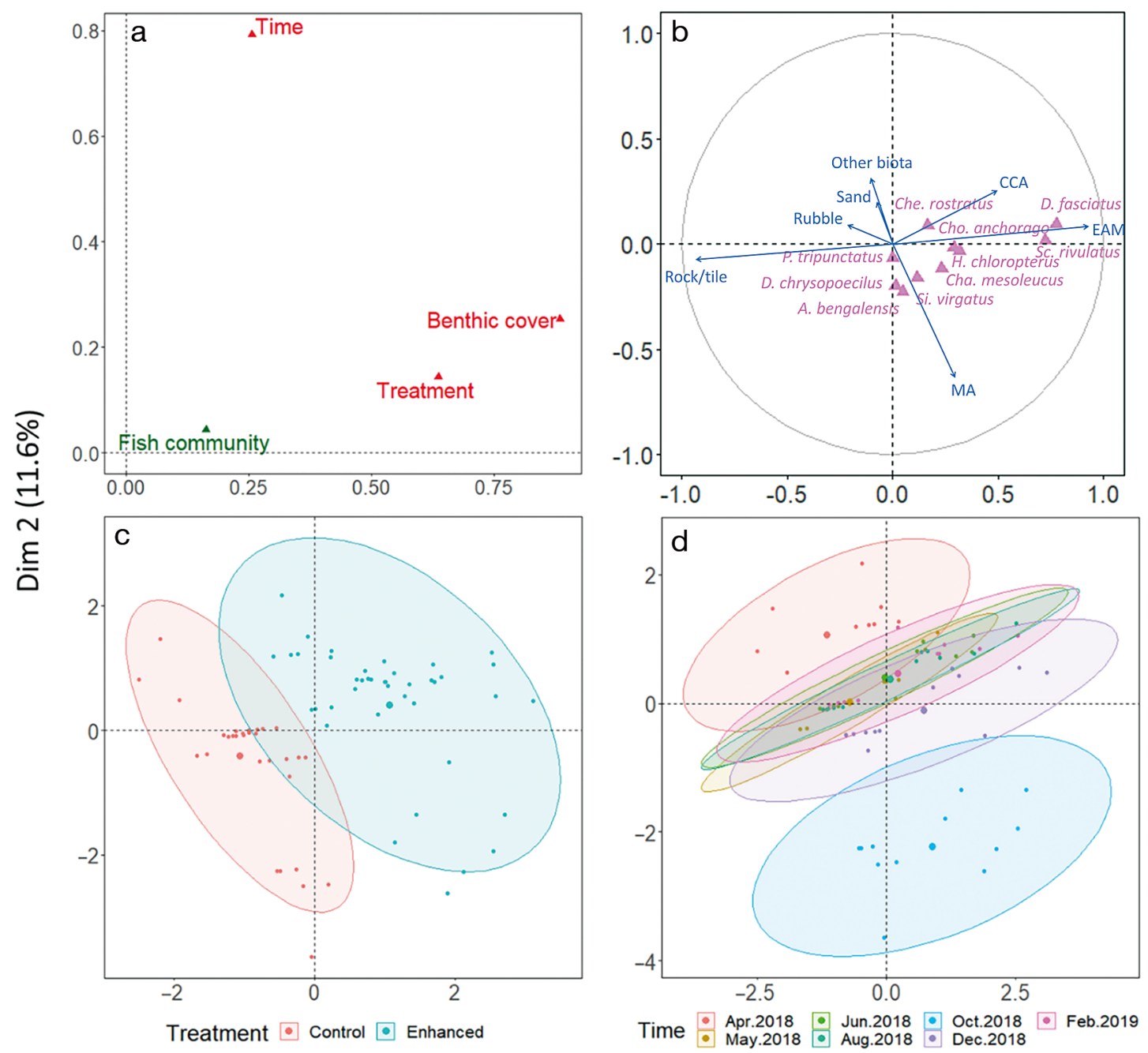

$\operatorname{Dim} 1(17.3 \%)$

Fig. 4. (a) Correlation between dimensions and explanatory variable groups; (b) bi-plot illustrating the relationship between benthic cover variables and the main epibenthic-feeding fish species and fish assemblage compositions grouped by (c) treatment and (d) time, with ellipses that capture $95 \%$ of the data. A: Abudefduf; Cha: Chaetodontoplus; Che: Chelmon; Cho: Choerodon; D: Dischistodus; H: Halichoeres; P: Pomacentrus; Sc: Scarus; Si: Siganus

food sources. Comprising filamentous algae, detritus, sediment and epifauna (Choat et al. 2002, Wilson et al. 2003), EAM is known to be an important food source for herbivorous and detritivorous fishes on coral reefs (Ceccarelli 2007, Bellwood \& Fulton 2008, Clements et al. 2017). High epifaunal abundance and diversity in EAM has been recorded in both temperate and tropical regions (Kramer et al. 2014, Loke et al. 2016) and in natural and artificial shorelines (Kramer et al. 2012, Heery et al. 2020). Harpacticoid copepods can be particularly abundant, and these make up a large proportion of various epibenthicfeeding fish diets (Kramer et al. 2013, 2015). This suggests that EAM not only serves as a food source for intertidal invertebrates (Lai et al. 2018), but is also a key grazing substrate for multiple fish species associated with seawalls.

Our data also revealed possible temporal trends in the fish assemblages utilising intertidal seawalls. Assemblage compositions in April and October were clearly different (Fig. 4d), presumably due to the species-specific occurrence of seasonal visitors at the study site. Most of the recorded species are typically known to inhabit coral reefs, and this temporal pattern coincides with 2 coral reef fish recruitment seasons in Singapore (Low \& Chou 1994, Low et al. 1997). In addition, some species may have been influenced by the seasonal change in surrounding habitats (Franzitta \& Airoldi 2019, Henderson et al. 2019). For example, for Sargassum ilicifolium, the 
most abundant Sargassum species on reef flats in Singapore and most abundant macroalgal species adjacent to the seawall study site, growth fluctuates dramatically, with the thallus length ranging from $9.9 \pm 0.5 \mathrm{~cm}$ in May to $110.4 \pm 2.4 \mathrm{~cm}$ in December (Low et al. 2019). Proliferation of this canopy-forming macroalgae can provide increased shelter for juvenile fishes (Evans et al. 2014) and attract piscivorous fishes (Zarco-Perello \& Enríquez 2019) such as Gnathanodon speciosus and Sphyraena flavicauda, which were recorded in our study, as well as macroalgae browsers such as $S$. virgatus (Bauman et al. 2017). Populations of 2 large territorial damselfish species, Dischistodus chrysopoecilus and D. prosopotaenia, also respond differently to seasonal Sargassum growth, with $D$. prosopotaenia moving to deeper waters as Sargassum thickens while D. chrysopoecilus remains in the reef flat (Low et al. 1997). This behaviour would explain the contrasting seasonal patterns of these 2 species.

Our study system and results are likely to have been influenced by positive ecological feedbacks from several of the dominant fish species we observed. Due to their abundance and substantial contribution to the total bites, D. fasciatus and S. rivulatus may have had important effects on the benthos within the enhanced seawall plots. Many territorial damselfishes, including $D$. fasciatus, tend to modify benthic communities by allowing growth of algal turfs in their territories (Ceccarelli 2007, Hoey \& Bellwood 2010). This behaviour could explain the positive relationship between $D$. fasciatus and EAM (Fig. 4b) in our study, although such effects are probably highly localised due to their relatively small territories (up to $6.3 \mathrm{~m}^{2}$; Hata \& Kato 2004, Ceccarelli et al. 2005). The influence of $S$. rivulatus on EAM-associated benthic communities is probably different from that of $D$. fasciatus, as it scrapes off the EAM and creates new space for other colonisers (Bonaldo \& Bellwood 2008). Further, additional feedbacks might result from complex interactions between epibenthic feeders and other taxa, such as phytal microinvertebrates; for instance, it has been estimated that $S$. rivulatus can consume nearly 10000 harpacticoids $\mathrm{m}^{-2} \mathrm{~d}^{-1}$ (Kramer et al. 2013), reflecting the importance of these copepods to the EAM epibiota.

In the face of continued ocean sprawl, there is increasing interest and demand for ecologically engineered habitats that enhance biodiversity and ecosystem services (Firth et al. 2016, Munsch et al. 2017, Burt \& Bartholomew 2019). Our findings suggest that microhabitat features commonly used to encourage invertebrate and macroalgae colonisation in the intertidal zone also benefit epibenthic-feeding fishes that forage in intertidal areas during high tide. This response may be trophic-mediated, with microhabitat features supporting larger crops of EAM, which, in turn, act as a food resource for epibenthic-feeding fish assemblages. This information adds to past and present research highlighting the likely importance of EAM in structuring intertidal communities on seawalls in Singapore (Lai et al. 2018, Heery et al. 2020). Moreover, regardless of the underlying mechanisms at play, the results indicate that both microhabitat and $\mathrm{cm}$ - to $\mathrm{m}$ - scale habitat features contribute to enhancement of nearshore fish assemblages. Because this study was conducted within m-scale plots, our results must be interpreted carefully, especially when extrapolating to large-scale ecological engineering interventions. Nonetheless, the results from our study and other similar small-scale experiments advance our understanding of how ecological engineering influences fish assemblages, knowledge that can inform large-scale deployments used in urban coastal management.

Acknowledgements. We thank the members of Experimental Marine Ecology Laboratory at National University of Singapore for their help in the field. This research was supported by the National Research Foundation, Prime Minister's Office, Singapore, under its Marine Science Research and Development Programme (Award No. MSRDP-05).

\section{LITERATURE CITED}

Allen GR, Erdmann MV (2012) Reef fishes of the East Indies, Vol 1-3. Tropical Reef Research, Perth

Bauman AG, Guest JR, Dunshea G, Low J, Todd PA, Steinberg PD (2015) Coral settlement on a highly disturbed equatorial reef system. PLOS ONE 10:e0127874

*Bauman AG, Hoey AS, Dunshea G, Feary DA, Low J, Todd PA (2017) Macroalgal browsing on a heavily degraded, urbanized equatorial reef system. Sci Rep 7:8352

*B Bellwood DR, Fulton CJ (2008) Sediment-mediated suppression of herbivory on coral reefs: Decreasing resilience to rising sea-levels and climate change? Limnol Oceanogr 53:2695-2701

Bennett S, Vergés A, Bellwood DR (2010) Branching coral as a macroalgal refuge in a marginal coral reef system. Coral Reefs 29:471-480

* Benzeev R, Hutchinson N, Friess DA (2017) Quantifying fisheries ecosystem services of mangroves and tropical artificial urban shorelines. Hydrobiologia 803:225-237

* Bergström L, Heikinheimo O, Svirgsden R, Kruze E and others (2016) Long term changes in the status of coastal fish in the Baltic Sea. Estuar Coast Shelf Sci 169:74-84

Bishop MJ, Mayer-Pinto M, Airoldi L, Firth LB and others (2017) Effects of ocean sprawl on ecological connectivity: impacts and solutions. J Exp Mar Biol Ecol 492:7-30

Bonaldo RM, Bellwood DR (2008) Size-dependent variation in the functional role of the parrotfish Scarus rivulatus on 
the Great Barrier Reef, Australia. Mar Ecol Prog Ser 360: 237-244

Brandl SJ, Bellwood DR (2014) Pair-formation in coral reef fishes: an ecological perspective. Oceanogr Mar Biol Annu Rev 52:1-80

Brandl SJ, Bellwood DR (2016) Microtopographic refuges shape consumer-producer dynamics by mediating consumer functional diversity. Oecologia 182:203-217

* Browne NK, Precht E, Last KS, Todd PA (2014) Photo-physiological costs associated with acute sediment stress events in three near-shore turbid water corals. Mar Ecol Prog Ser 502:129-143

Burke L, Reytar K, Spalding M, Perry A (2011) Reefs at risk revisited. World Resource Institute, Washington, DC

Burt JA, Bartholomew A (2019) Towards more sustainable coastal development in the Arabian Gulf: opportunities for ecological engineering in an urbanized seascape. Mar Pollut Bull 142:93-102

* Burt J, Bartholomew A, Usseglio P, Bauman A, Sale PF (2009) Are artificial reefs surrogates of natural habitats for corals and fish in Dubai, United Arab Emirates? Coral Reefs 28:663-675

Burt JA, Feary DA, Cavalcante G, Bauman AG, Usseglio P (2013) Urban breakwaters as reef fish habitat in the Persian Gulf. Mar Pollut Bull 72:342-350

* Ceccarelli DM (2007) Modification of benthic communities by territorial damselfish: a multi-species comparison. Coral Reefs 26:853-866

Ceccarelli DM, Jones GP, McCook LJ (2005) Effects of territorial damselfish on an algal-dominated coastal coral reef. Coral Reefs 24:606-620

Chia LS, Khan H, Chou LM (1988) The coastal environmental profile of Singapore. ICLARM Technical Report No. 21. International Center for Living Aquatic Resources Management (ICLARM), Manila

* Choat JH, Clements KD, Robbins WD (2002) The trophic status of herbivorous fishes on coral reefs. Mar Biol 140: 613-623

Chou LM (2008) Nature and sustainability of the marine environment. In: Wong TC, Yuen B, Goldblum C (eds) Spatial planning for a sustainable Singapore. Springer Science and Business Media, Dordrecht, p 169-182

Clements KD, German DP, Piché J, Tribollet A, Choat JH (2017) Integrating ecological roles and trophic diversification on coral reefs: multiple lines of evidence identify parrotfishes as microphages. Biol J Linn Soc 120: 729-751

Clynick BG, Chapman MG, Underwood AJ (2008) Fish assemblages associated with urban structures and natural reefs in Sydney, Australia. Austral Ecol 33:140-150

Coombes MA, La Marca EC, Naylor LA, Thompson RC (2015) Getting into the groove: opportunities to enhance the ecological value of hard coastal infrastructure using fine-scale surface textures. Ecol Eng 77:314-323

*Dafforn KA, Mayer-Pinto M, Morris RL, Waltham NJ (2015) Application of management tools to integrate ecological principles with the design of marine infrastructure. J Environ Manage 158:61-73

Duarte CM, Dennison WC, Orth RJW, Carruthers TJB (2008) The charisma of coastal ecosystems: addressing the imbalance. Estuaries Coasts 31:233-238

Erftemeijer PLA, Riegl B, Hoeksema BW, Todd PA (2012) Environmental impacts of dredging and other sediment disturbances on corals: a review. Mar Pollut Bull 64: 1737-1765
Evans RD, Wilson SK, Field SN, Moore JAY (2014) Importance of macroalgal fields as coral reef fish nursery habitat in north-west Australia. Mar Biol 161:599-607

Fabricius KE (2005) Effects of terrestrial runoff on the ecology of corals and coral reefs: review and synthesis. Mar Pollut Bull 50:125-146

Firth LB, Knights AM, Bridger D, Evans AJ and others (2016) Ocean sprawl: challenges and opportunities for biodiversity management in a changing world. Oceanogr Mar Biol Annu Rev 54:201-278

Fox RJ, Bellwood DR (2013) Niche partitioning of feeding microhabitats produces a unique function for herbivorous rabbitfishes (Perciformes, Siganidae) on coral reefs. Coral Reefs 32:13-23

Franzitta G, Airoldi L (2019) Fish assemblages associated with coastal defence structures: Does the surrounding habitat matter? Reg Stud Mar Sci 31:100743

*Gatwicke B, Speight MR (2005) Effects of habitat complexity on Caribbean marine fish assemblages. Mar Ecol Prog Ser 292:301-310

*Guest JR, Tun K, Low J, Vergés A and others (2016) 27 years of benthic and coral community dynamics on turbid, highly urbanised reefs off Singapore. Sci Rep 6:36260

Guidetti P, Bussotti S, Boero F (2005) Evaluating the effects of protection on fish predators and sea urchins in shallow artificial rocky habitats: a case study in the northern Adriatic Sea. Mar Environ Res 59:333-348

*Hartig F (2019) DHARMa: residual diagnostics for hierarchical (multilevel/mixed) regression models. R package version 0.2.6. https://cran.r-project.org/web/packages/ DHARMa/

Hata H, Kato M (2004) Monoculture and mixed-species algal farms on a coral reef are maintained through intensive and extensive management by damselfishes. J Exp Mar Biol Ecol 313:285-296

* Heery EC, Hoeksema BW, Browne NK, Reimer JD and others (2018) Urban coral reefs: degradation and resilience of hard coral assemblages in coastal cities of East and Southeast Asia. Mar Pollut Bull 135:654-681

*Heery EC, Oh RKE, Taira D, Ng D and others (2020) Human-engineered hydrodynamic regimes as a driver of cryptic microinvertebrate assemblages on urban artificial shorelines. Sci Total Environ 725:138348

*Henderson CJ, Gilby BL, Schlacher TA, Connolly RM and others (2019) Contrasting effects of mangroves and armoured shorelines on fish assemblages in tropical estuarine seascapes. ICES J Mar Sci 76:1052-1061

Hixon MA, Beets JP (1993) Predation, prey refuges, and the structure of coral-reef fish assemblages. Ecol Monogr 63: 77-101

*Hoey AS, Bellwood DR (2010) Damselfish territories as a refuge for macroalgae on coral reefs. Coral Reefs 29: $107-111$

Jaafar Z, Hajisamae S, Chou LM, Yatiman Y (2004) Community structure of coastal fishes in relation to heavily impacted human modified habitats. Hydrobiologia 511: 113-123

Kassambara A, Mundt F (2019) factoextra: extract and visualize the results of multivariate data analyses. R package version 1.0.6. https://cran.r-project.org/web/packages/ factoextra/

Kohler KE, Gill SM (2006) Coral point count with excel extensions (CPCe): a visual basic program for the determination of coral and substrate coverage using random point count methodology. Comput Geosci 32:1259-1269 
Kramer MJ, Bellwood DR, Bellwood O (2012) Cryptofauna of the epilithic algal matrix on an inshore coral reef, Great Barrier Reef. Coral Reefs 31:1007-1015

Kramer MJ, Bellwood O, Bellwood DR (2013) The trophic importance of algal turfs for coral reef fishes: the crustacean link. Coral Reefs 32:575-583

Kramer MJ, Bellwood DR, Bellwood O (2014) Large-scale spatial variation in epilithic algal matrix cryptofaunal assemblages on the Great Barrier Reef. Mar Biol 161: 2183-2190

Kramer MJ, Bellwood O, Fulton CJ, Bellwood DR (2015) Refining the invertivore: diversity and specialisation in fish predation on coral reef crustaceans. Mar Biol 162: 1779-1786

Lai S, Loke LHL, Hilton MJ, Bouma TJ, Todd PA (2015) The effects of urbanisation on coastal habitats and the potential for ecological engineering: a Singapore case study. Ocean Coast Manage 103:78-85

Lai S, Loke LHL, Bouma TJ, Todd PA (2018) Biodiversity surveys and stable isotope analyses reveal key differences in intertidal assemblages between tropical seawalls and rocky shores. Mar Ecol Prog Ser 587:41-53

Lanham BS, Vergés A, Hedge LH, Johnston EL, Poore AG (2018) Altered fish community and feeding behaviour in close proximity to boat moorings in an urban estuary. Mar Pollut Bull 129:43-51

* Lê S, Josse J, Husson F (2008) FactoMineR: an R package for multivariate analysis. J Stat Softw 25:1-18

* Loke LHL, Todd PA (2016) Structural complexity and component type increase intertidal biodiversity independently of area. Ecology 97:383-393

Loke LHL, Liao LM, Bouma TJ, Todd PA (2016) Succession of seawall algal communities on artificial substrates. Raffles Bull Zool 32:1-10

Loke LHL, Bouma TJ, Todd PA (2017) The effects of manipulating microhabitat size and variability on tropical seawall biodiversity: field and flume experiments. J Exp Mar Biol Ecol 492:113-120

* Loke LHL, Chisholm RA, Todd PA (2019) Effects of habitat area and spatial configuration on biodiversity in an experimental intertidal community. Ecology 100(8): e02757

Low JKY, Chou LM (1994) Observations on coral reef fish recruitment in Singapore. In: Sudara S, Wilkinson CR, Chou LM (eds) Proc $3^{\text {rd }}$ ASEAN-Australia symposium on living coastal resources, Vol 2. Chulalonkorn University, Bangkok, p 229-233

Low JKY, Leng CB, Chou LM (1997) Pomacentrid population dynamics on Singapore coral reefs. Environ Monit Assess 44:53-66

Low JK, Fong J, Todd PA, Chou LM, Bauman AG (2019) Seasonal variation of Sargassum ilicifolium (Phaeophyceae) growth on equatorial coral reefs. J Phycol 55:289-296

Ménard A, Turgeon K, Roche DG, Binning SA, Kramer DL (2012) Shelters and their use by fishes on fringing coral reefs. PLOS ONE 7:e38450

Mercader M, Mercière A, Saragoni G, Cheminée A and others (2017) Small artificial habitats to enhance the nursery function for juvenile fish in a large commercial port of the Mediterranean. Ecol Eng 105:78-86

Morais RA, Bellwood DR (2019) Pelagic subsidies underpin fish productivity on a degraded coral reef. Curr Biol 29: 1521-1527

Morris RL, Chapman MG, Firth LB, Coleman RA (2017) Increasing habitat complexity on seawalls: investigating large-and small-scale effects on fish assemblages. Ecol Evol 7:9567-9579

Morris RL, Porter AG, Figueira WF, Coleman RA, Fobert EK, Ferrari R (2018) Fish-smart seawalls: a decision tool for adaptive management of marine infrastructure. Front Ecol Environ 16:278-287

Morris RL, Heery EC, Loke LHL, Lau E and others (2019) Design options, implementation issues and evaluating success of ecologically engineered shorelines. Oceanogr Mar Biol Annu Rev 57:169-228

Munsch SH, Cordell JR, Toft JD (2015a) Effects of shoreline engineering on shallow subtidal fish and crab communities in an urban estuary: a comparison of armored shorelines and nourished beaches. Ecol Eng 81:312-320

Munsch SH, Cordell JR, Toft JD (2015b) Effects of seawall armoring on juvenile Pacific salmon diets in an urban estuarine embayment. Mar Ecol Prog Ser 535:213-229

Munsch SH, Cordell JR, Toft JD (2016) Fine-scale habitat use and behavior of a nearshore fish community: nursery functions, predation avoidance, and spatiotemporal habitat partitioning. Mar Ecol Prog Ser 557:1-15

*Munsch SH, Cordell JR, Toft JD (2017) Effects of shoreline armouring and overwater structures on coastal and estuarine fish: opportunities for habitat improvement. J Appl Ecol 54:1373-1384

*Nash KL, Graham NA, Wilson SK, Bellwood DR (2013) Cross-scale habitat structure drives fish body size distributions on coral reefs. Ecosystems 16:478-490

Pagès J (2004) Multiple factor analysis: main features and application to sensory data. Rev Colomb Estad 27:1-26

* Porter AG, Ferrari RL, Kelaher BP, Smith SDA, Coleman RA, Byrne M, Figueira W (2018) Marine infrastructure supports abundant, diverse fish assemblages at the expense of beta diversity. Mar Biol 165:112

R Core Team (2019) R: a language and environment for statistical computing. R Foundation for Statistical Computing, Vienna

Riegl B (2001) Degradation of reef structure, coral and fish communities in the Red Sea by ship groundings and dynamite fisheries. Bull Mar Sci 69:595-611

* Seitz RD, Wennhage H, Bergström U, Lipcius RN, Ysebaert $\mathrm{T}$ (2014) Ecological value of coastal habitats for commercially and ecologically important species. ICES J Mar Sci 71:648-665

* Sella I, Perkol-Finkel S (2015) Blue is the new green-ecological enhancement of concrete based coastal and marine infrastructure. Ecol Eng 84:260-272

* Smithson M, Verkuilen J (2006) A better lemon squeezer? Maximum-likelihood regression with beta-distributed dependent variables. Psychol Methods 11:54-71

Strain EMA, Morris RL, Coleman RA, Figueira WF, Steinberg PD, Johnston EL, Bishop MJ (2018a) Increasing microhabitat complexity on seawalls can reduce fish predation on native oysters. Ecol Eng 120:637-644

Strain EMA, Olabarria C, Mayer-Pinto M, Cumbo V and others (2018b) Eco-engineering urban infrastructure for marine and coastal biodiversity: Which interventions have the greatest ecological benefit? J Appl Ecol 55: 426-441

Taira D, Poquita-Du RC, Toh TC, Toh KB and others (2018) Spatial variability of fish communities in a highly urbanised reef system. Urban Ecosyst 21:85-95

Tessier E, Chabanet P, Pothin K, Soria M, Lasserre G (2005) Visual censuses of tropical fish aggregations on artificial 
reefs: slate versus video recording techniques. J Exp Mar Biol Ecol 315:17-30

Todd PA, Heery EC, Loke LHL, Thurstan RH, Kotze DJ, Swan C (2019) Towards an urban marine ecology: characterizing the drivers, patterns and processes of marine ecosystems in coastal cities. Oikos 128:1215-1242

Toft JD, Ogston AS, Heerhartz SM, Cordell JR, Flemer EE (2013) Ecological response and physical stability of habitat enhancements along an urban armored shoreline. Ecol Eng 57:97-108

Toh KB, Ng CSL, Leong WKG, Jaafar Z, Chou LM (2016) Assemblages and diversity of fishes in Singapore's marinas. Raffles Bull Zool 32:85-94

Ushiama S, Mayer-Pinto M, Bugnot AB, Johnston EL, Dafforn KA (2019) Eco-engineering increases habitat availability and utilisation of seawalls by fish. Ecol Eng 138: 403-411

Editorial responsibility: Laura Falkenberg (Guest Editor), Hong Kong, SAR

Reviewed by: 3 anonymous referees
Wang YI, Naumann U, Wright ST, Warton DI (2012) mvabund-an $\mathrm{R}$ package for model-based analysis of multivariate abundance data. Methods Ecol Evol 3: 471-474

Weis JS, Weis P (2005) Use of intertidal mangrove and sea wall habitats by coral reef fishes in theWakatobi Marine Park, Indonesia. Raffles Bull Zool 53:119-124

Wilson SK, Bellwood DR, Choat JH, Furnas MJ (2003) Detritus in the epilithic algal matrix and its use by coral reef fishes. Oceanogr Mar Biol Annu Rev 41:279-310

*Wilson SK, Graham NAJ, Polunin NVC (2007) Appraisal of visual assessments of habitat complexity and benthic composition on coral reefs. Mar Biol 151:1069-1076

Zarco-Perello S, Enríquez S (2019) Remote underwater video reveals higher fish diversity and abundance in seagrass meadows, and habitat differences in trophic interactions. Sci Rep 9:6596

Submitted: February 10, 2020

Accepted: August 6, 2020

Proofs received from author(s): October 7, 2020 